\title{
A história de 35 anos do Programa de Educação Tutorial - Biologia na Universidade Federal de Viçosa
}

\author{
Mara Garcia Tavares ${ }^{1}$, Lucio Antonio de Oliveira \\ Campos $^{2}$, Julia Martins de Andrade
}

Resumo: O Programa de Educação Tutorial foi criado em 1979 com o objetivo de elevar a qualificação dos estudantes de cursos superiores, nas diversas áreas do conhecimento. O PET Biologia da Universidade Federal de Viçosa, em particular, foi implementado em março de 1985. O objetivo deste artigo é resgatar o processo de criação do mesmo e contar um pouco de sua história. Pretende-se ressaltar as atividades desenvolvidas pelo grupo em diferentes momentos da sua trajetória e, as contribuições do Programa para a formação de seus participantes. A análise realizada evidenciou que a metodologia adotada no Programa propiciou oportunidades para que novos conhecimentos sejam adquiridos ao longo do tempo de permanência dos bolsistas no Programa. Ela também permite aos petianos enriquecer sua formação geral, melhorando sua capacidade de trabalhar em equipe e de resolver problemas. Estas características aumentam a criatividade e despertam novos interesses nos petianos. O Programa, portanto, contribui para a formação acadêmica global dos discentes do Curso.

Palavras-chave: Educação tutorial. Formação discente. Políticas públicas.

Área Temática: Políticas Públicas.

\section{The 35-year history of the Tutorial Education Program - Biology at the Federal University of Viçosa}

\begin{abstract}
The Tutorial Education Program was created in 1979 with the objective of raising the qualification of students of higher education courses in the various areas of knowledge. The PET Biology of the Federal University of Viçosa, in particular, was implemented in March 1985. The objective of this article is to rescue its process of creation and tell a little of its history. It is intended to highlight the activities developed by the group at different moments of its trajectory and the contributions of the Program to the formation of its participants. The analysis showed that the methodology adopted in the Program provided opportunities for new knowledge to be acquired over the time of permanence of the scholarship holders in the Program. It also allows undergraduats to enrich their general training, improving their ability to work as a team and solve problems. These characteristics increase creativity and awaken new interests. The Program, therefore, contributes to the global academic education of the students.
\end{abstract}

Keywords: Tutorial education. Student training. Public policy.

\footnotetext{
${ }^{1}$ Professora Titular do Departamento de Biologia Geral da Universidade Federal de Viçosa - UFV, Viçosa - MG, Brasil. Atual Tutora do PET/Biologia da UFV. Endereço: Avenida Peter Henry Rolfs, s/n - Campus Universitário, 36570-900 - Viçosa-MG Brasil.Telefone (31)3612 5010.Email:mtavares@ufv.br

${ }^{2}$ Professor Titular Aposentado do Departamento de Biologia Geral da Universidade Federal de Viçosa - UFV. Primeiro Tutor do grupo PET/Biologia da UFV

${ }^{3}$ Graduanda do Curso de Ciências Biológicas da Universidade Federal de Viçosa. Bolsista do PET/Biologia - UFV
} 


\section{Los 35 años de historia del Programa de Educación Tutorial - Biología en la Universidad Federal de Viçosao}

Resumen: El Programa de Educación Tutorial fue creado en 1979 con el objetivo de elevar la calificación de los estudiantes de cursos de educación superior en las diversas áreas del conocimiento. El PET Biología de la Universidad Federal de Viçosa, en particular, se implementó en marzo de 1985. El objetivo de este artículo es rescatar el proceso de creación de lo mismo y contar un poco de su historia. También se pretende destacar las actividades desarrolladas por el grupo en diferentes momentos de su trayectoria y las aportaciones del Programa a la formación de sus participantes. El análisis mostró que la metodología adoptada en el Programa brindó oportunidades para que se adquirieron nuevos conocimientos en el tiempo de permanencia de los becarios en el Programa. Tambiém permite a los alumnos enriquecer su formación general, mejorando su capacidad para trabajar en equipo y resolver problemas. Estas características aumentan la creatividad y despiertan nuevos intereses. El Programa, por lo tanto, contribuye a la formación académica general de los alumnos del Curso.

Palabras clave: Educación tutorial. Formación estudiantil. Políticas públicas.

\section{INTRODUÇÃO}

A criação do Programa Especial de Treinamento (PET) ocorreu em 1979, quando o professor Cláudio de Moura Castro era o diretor da CAPES. Este programa tentou replicar uma experiência bastante exitosa -o "Sistema de Bolsas" - que havia sido implantada na década de 1950, na recém-criada Faculdade de Ciências Econômicas da UFMG (FACE). Na época, o diretor da FACE era o professor Ivon Leite de Magalhães Pinto. Muitos dos alunos que participaram desse programa deram origem a um grupo de profissionais que se notabilizou pela qualificação e liderança em suas áreas de atuação (CASTRO, 2001).

O objetivo do Programa criado pela CAPES era elevar a qualificação dos estudantes de cursos superiores, nas diversas áreas do conhecimento. Nessa ocasião, já haviam sido implantados diversos Programas de Pósgraduação no Brasil e o ingresso em um desses Programas era importante fator para a qualificação profissional dos egressos dos cursos superiores. Participar de um programa de Pós-graduação também poderia garantir boas colocações no mercado de trabalho e liderança em suas áreas de atuação. Os participantes do antigo "Sistema de Bolsas" da FACE haviam se notabilizado pelo sucesso em ingressar em Programas de Pós-Graduação, o que, pelo menos em parte, colaborou para o sucesso dos mesmos e esse foi um dos objetivos iniciais do PET.

A partir de 1995, iniciou-se um período durante o qual houve algumas tentativas de se acabar com o PET, sendo o mesmo transferido da CAPES para a Secretaria de Educação Superior do Ministério da Educação (SESu/MEC), em 1999. A situação começou a se normalizar em 2002 e entre as modificações ocorridas, o Programa passou a se chamar "Programa de Educação Tutorial", mantendo a sigla PET (MULLER, 2003; MELO FILHO, 2019).

Atualmente, existem 842 grupos PET no Brasil, distribuídos em 121 Instituições de Ensino Superior, 18 das quais se localizam em Minas Gerais (BRASIL, 2020). Na Universidade Federal de Viçosa (UFV), no momento, existem oito grupos PET (Administração, Biologia, Bioquímica, Educação, Educação [Campus Florestal], Engenharia Agrícola e Ambiental, Engenharia de Produção e Nutrição). De 1994 até janeiro de 2020 existia, ainda, o PET Economia Doméstica, que encerrou suas atividades devido à extinção do referido curso. 
O PET/Biologia, em particular, foi o primeiro grupo PET a ser implementado na UFV, em março de 1985. Atualmente, o grupo é composto por 12 discentes bolsistas, três discentes não bolsistas e um professor Tutor. A filosofia do Programa, seguida pelo grupo, baseia-se no desenvolvimento de um conjunto de atividades de ensino, de pesquisa e de extensão coletivamente organizadas, com relações horizontalizadas e diversificadas. Estas atividades visam diversificar a formação acadêmica/pessoal de seus participantes, complementando as atividades propostas na matriz curricular do Curso. Adicionalmente, como ficará claro ao longo deste artigo, as atividades desenvolvidas pelo grupo também têm como objetivo estimular a cidadania e a consciência social de todos os seus participantes. Muitas das atividades desenvolvidas envolvem uma interação contínua e intencional entre integrantes doPET e os demais discentes dos cursos de graduação em Ciências Biológicas e Licenciatura em Ciências Biológicas da UFV, entre outros. Desta forma, espera-se contribuir com a formação global destes discentes e ampliar a atuação dos petianos como agentes multiplicadores e disseminadores de novas ideias e práticas.

\section{OBJETIVOS}

O objetivo deste artigo é, em comemoração aos 35 anos de existência do grupo PET/Biologia da UFV, resgatar o processo de criação do mesmo e contar um pouco de sua história. Especificamente, ele tem como objetivo ressaltar as atividades de ensino, pesquisa e extensão desenvolvidas pelo grupo, em diferentes momentos da sua trajetória. Adicionalmente, objetivou-se identificar as contribuições do Programa para a formação de seus participantes.

\section{METODOLOGIA}

Para a elaboração desse artigo, inicialmente buscou-se analisar as principais legislações que regulamentaram e ainda regulamentam o Programa de Educação Tutorial. Realizou-se também uma revisão bibliográfica sobre os principais acontecimentos que marcaram os 40 anos de existência do Programa. Esses dados foram importantes para que se pudesse contextualizar, temporalmente, as diferentes fases do Programa e as alterações filosóficas sofridas pelo mesmo, desde sua criação.

Na sequência, analisamos os diversos relatórios de atividades produzidos pelo grupo, desde sua criação, em 1985. Esta análise deixou claro como os diferentes contextos histórico-políticos foram absorvidos pelo grupo e como o grupo adequou suas atividades, em cada situação. Ela também permitiu elencar uma série de atividades que são sistematicamente desenvolvidas pelo grupo e outras que ocorreram e ocorrem esporadicamente. A importância destas atividades para a formação dos discentes que participam do Programa será discutida ao longo do texto.

Ao mesmo tempo, elaborou-se um questionário para os ex-tutores do PET/Biologia da UFV para resgatar o processo de criação do grupo e verificar os desafios/dificuldades de se tutorar o grupo, em diferentes momentos 
de sua trajetória. Esse questionário buscava também obter as impressões dos ex-tutores sobre a influência do Programa para a formação acadêmica/pessoal de todos os envolvidos.

Um questionário específico para os ex-petianos do grupo também foi elaborado, a fim de atualizar o banco de dados dos egressos do Programa, mantido pelo grupo e obter opiniões sobre as contribuições do Programa para a formação pessoal e profissional dos mesmos. O contato com os ex-petianos foi realizado por e-mail e também através do compartilhamento do questionário nas redes sociais do grupo.

Nós também realizamos uma análise comparativa do tempo médio necessário para a conclusão do curso de graduação, coeficiente de rendimento e taxa de evasão entre ex-petianos e demais alunos do curso (que não participaram do Programa). Essa análise envolveu o período de 1982 (ano de ingresso no curso, de uma das petianas que participou da primeira turma do PET/Biologia da UFV) a 2019. Os dados para essa análise foram fornecidos pelo Serviço de Registro Escolar da UFV.

\section{RESULTADOS E DISCUSSÃO}

\section{História da criação do PET/Biologia na UFV}

A elaboração do projeto para a criação do PET/Biologia na UFV iniciou-se em 1984. Neste ano, o então Diretor do Centro de Ciências Biológicas e da Saúde, Prof. José Carlos Silva, informou o Prof. Lucio Antonio de Oliveira Campos, do Departamento de Biologia Geral, sobre a possibilidade de implantar o Programa na UFV e o convidou para organizar o mesmo.

Segundo o Prof. Lucio, a principal motivação para participar da organização do PET/Biologia foi

a possibilidade de atuar em um programa que visa dar aos alunos uma formação geral, bem mais ampla que aquela que se pretende com o Programa de Iniciação Científica.

O Programa, aprovado pela CAPES, começou a funcionar na UFV no dia 6 de março de 1985, com a indicação de cinco discentes bolsistas, selecionados com base no rendimento acadêmico e do prof. Lucio como primeiro tutor do grupo. De acordo com o Prof. Lucio,

a principal dificuldade para implantação do PET/Biologia foi a alocação de um espaço físico para os estudantes, o que é indispensável para o funcionamento do Programa e difícil de conseguir, especialmente na UFV, naquela ocasião.

Inicialmente o Programa foi instalado em uma sala, já utilizada pelo professor Lucio, no Apiário da UFV, com alguns móveis cedidos pela UFV. Esse foi um período de aprendizagem, especialmente para o tutor, de como fazer funcionar um Programa com as características do PET. As atividades desenvolvidas nesse período visavam o amadurecimento das habilidades pessoais dos bolsistas (oratória, argumentação e persuasão) e interpessoais (trabalho em grupo, respeito, liderança, criticidade e pró-atividade). Entre elas, pode-se citar a realização de reuniões; apresentação de seminários; leitura de textos científicos; participação em palestras, filmes, 
eventos científicos e cursos extracurriculares (incluindo o de língua estrangeiras). Os bolsistas também desenvolviam e apresentavam monografias em diferentes áreas de interesse, assim como visitavam museus, instituições de pesquisa ou ensino e empresas na área de atuação do biólogo. Eles também elaboravam informativos e minicursos para os demais alunos da graduação.

No final do ano de 1985, o Prof. Lucio solicitou seu desligamento como tutor e foi substituído pela profa. Aristéa Alves Azevedo, que já participava das atividades do grupo, como colaboradora.

Segundo a Profa. Aristéa, atuar como tutora foi

\begin{abstract}
Um desafio! A tarefa de programar atividades extracurriculares que despertassem o interesse de todos e que estimulassem a aprendizagem ativa e o desenvolvimento do pensamento crítico foi uma experiência árdua, mas recompensadora. As discussões no grupo eram bastante produtivas e ocorriam num ambiente informal contribuindo para aprimorar o trabalho em equipe desde a programação das atividades até a execução e avaliação final. Tudo era resolvido em conjunto o que colaborava para que as diferenças individuais fossem respeitadas e valorizadas e os eventuais conflitos minimizados. Harmonizar as diferentes áreas de interesse dos bolsistas e equilibrar as atividades para oferecer uma ampla gama de oportunidades não foi uma tarefa simples.
\end{abstract}

Ela destaca que seu o maior desafio como tutora foi promover a integração dos petianos com os demais alunos e docentes do Curso, além de convencê-los de que o PET era um patrimônio do Curso, não restrito aos bolsistas, e que podia melhorar a qualidade da formação dos alunos como um todo, pois, na época,

o PET era um programa novo (com pequeno número de bolsas) e, inicialmente, os demais alunos do curso (não bolsistas) consideravam os petianos como um grupo de privilegiados e o programa elitista. Os alunos demonstravam preconceito e, muitas vezes, resistência em participar das atividades promovidas pelo PET.

No período de 1986 a 1989, o Programa passa pela "fase de institucionalização". ACAPES publica o primeiro "Manual de orientações básicas do PET", que orientou o funcionamento do Programa durante vários anos (DESSEN, 1995; MELO FILHO, 2019). O número de grupos e de bolsistas aumenta e a relação com as Universidades se aperfeiçoa.

Na UFV, o PET/Biologia tutorado pela professora Aristéa passou a contar com nove bolsistas, a partir de dezembro de 1986. Em setembro de 1987, ano de seu afastamento para realização de doutorado na USP, a professora Aristéa foi substituída na tutoria do PET pela professora Irani Quagio-Grassioto, auxiliada pelo Professor Lucio.

O período de 1986 a1989 foi muito importante para a consolidação do Programa na UFV, tanto do ponto de vista de seu funcionamento quanto do ponto de vista físico. Diversas das atividades que começaram a ser organizadas nessa ocasião são realizadas com sucesso até hoje. Salienta-se que várias dessas atividades são realizadas com a colaboração de professores de diversos departamentos da Universidade. Adicionalmente, a indispensável biblioteca do PET foi organizada, móveis e equipamentos foram adquiridos e foram feitas gestões no sentido de se encontrar um espaço físico definitivo e adequado para a instalação do grupo. 
Em 1989, a professora Irani sai da UFV e é substituída na tutoria do PET pelo professor Lucio, auxiliado na condução do grupo pela professora Silvia das Graças Pompolo, até março de 1992.

Atividades que visavam uma maior interação com a comunidade extra universitária e que haviam sido organizadas já no período de 1986 a 1989, como o "PET na Praça” e o "PET na Escola”, tiveram continuidade. Ao mesmo tempo, foram mantidas atividades que visavam maior interação com a comunidade universitária, como a divulgação do "Informativo" e a realização de palestras, seminários, cursos extracurriculares.

Para ajudar no desenvolvimento e aperfeiçoamento de habilidades pessoais, o grupo continuou realizando a leitura e discussão de textos científicos, a apresentação de filmes diversos, a participação em cursos de língua estrangeira, os estágios extracurriculares e a apresentação de seminários. Nesse período, foram estimuladas as visitas técnicas/culturais, mesmo que individuais, além das visitas em grupo, facilitadas pela verba de custeio fornecida pela CAPES.

Em 1989, a CAPES inicia a expansão dos grupos e entre 1990 e 1992, o número de grupos mais que triplica (DESSEN, 1995). No período, houve atraso no pagamento das bolsas e das "taxas acadêmicas", o que dificultou a realização de muitas das atividades programadas e gerou grande apreensão nos participantes do Programa.

A situação se normaliza momentaneamente durante a "fase de consolidação" do programa que, porém, durou apenas um ano (1993-1994 - DESSEN, 1995; MELO FILHO, 2019). Nesse curto espaço de tempo, entretanto, o grupo foi capaz de se reorganizar e voltar a desenvolver atividades direcionadas para a comunidade e para os demais alunos do curso de Ciências Biológicas (informativos, Curso de Educação Ambiental "Fora da sala de Aula", atividades práticas para alunos do Ensino Médio e recepção de calouros). Em 1993, o grupo criou um questionário para analisar as impressões dos ex-petianos sobre o Programa, o que representou a primeira iniciativa de se construir um banco de dados dos egressos do PET/Biologia.

A partir de 1995, inicia-se um período durante o qual a CAPES resolve encerrar as atividades do Programa alegando 1) o alto custo, 2) que o mesmo estava apenas preparando os bolsistas para o ingresso em Programas de Pós-graduação e 3) que o Programa havia se afastado da meritocracia, tanto no que se refere à escolha de bolsistas quanto de tutores. Nesse período, a CAPES solicita duas avaliações externas que concluem que o Programa é bom e atende plenamente aos objetivos para os quais foi criado (MELO FILHO, 2019). Ainda assim, o objetivo de acabar com o PET é mantido.

Apesar das dificuldades, consequência do atraso das bolsas e taxas acadêmicas e da incerteza quanto ao futuro do Programa, os grupos mantiveram o engajamento. Com ajuda das Universidades, eles continuaram ativos e conseguiram realizar suas atividades, algumas das quais muito importantes para o futuro do Programa. Na UFV, por exemplo, o PET/Biologia foi instalado em uma casa própria, na Vila Gianetti. A mudança para a "casa do PET/Biologia" possibilitou a organização de diferentes espaços (biblioteca, sala de estudo, laboratório, sala de reuniões), otimizando a realização das atividades do grupo e, até hoje, representa um espaço importante para a realização dessas atividades. 
Neste período, com o intuito de conhecer a realidade de outras instituições e as características de outros Cursos de Ciências Biológicas, o grupo passa a desenvolver atividades em conjuntos com outros PETs Ciências Biológicas do País. A primeira dessas atividades foi a visita do grupo da UNESP de Rio Claro - SP a Viçosa, no final de 1994. Nesta oportunidade, o grupo de Rio Claro pode conhecer o Campus da UFV e alguns espaços físicos de interesse. Adicionalmente, os dois grupos visitaram várias igrejas, prédios e monumentos históricos de Ouro Preto e Mariana - MG, além da coleção de fósseis da PUC/MG e dos Museus de Paleontologia e arqueologia da UFMG, em Belo Horizonte. A visita se encerrou com uma excursão à Serra do Cipó. Em contrapartida, em fevereiro de 1995, o grupo de Viçosa visitou o grupo PET/Ciências Biológicas da UNESP de Rio Claro, conhecendo as linhas de pesquisa e alguns projetos desenvolvidos no Instituto de Biociências. Os dois grupos ainda visitaram uma área de conservação ambiental (Núcleo de Picinguaba) em Ubatuba e o patrimônio histórico da cidade de Parati. Visitas semelhantes são realizadas posteriormente, em conjunto com os PETs de Ciências Biológicas da PUC de Belo Horizonte (1996) e São José do Rio Preto - SP (1997).

Essas atividades foram importantes porque permitiram a troca ideias entre bolsistas e tutores de diferentes Programas, o compartilhamento de experiências e visitas a instituições voltadas para atividades científicas e culturais localizadas fora de Viçosa.

O grupo também participou de vários encontros locais, regionais e nacionais dos grupos PET, além de continuarem a desenvolver suas atividades regulares.

Como a intenção de extinguir o Programa foi mantida, iniciou-se a chamada "fase de resistência" (19992000), marcada pela intensificação das mobilizações e manifestações em apoio à preservação do programa (MULLER, 2003; MELO FILHO, 2019). Os grupos PET da UFV, existentes na ocasião, tiveram participação ativa nesse movimento, que recebeu amplo apoio, inclusive de parlamentares. Com essas mobilizações, o Programa acabou sendo transferido da CAPES para o Departamento de projetos Especiais de Modernização e Qualificação do Ensino Superior (DEPEM), órgão da Secretaria de Ensino Superior do MEC (SESu/MEC) (MELO FILHO, 2019).

A intenção de extinguir o Programa, entretanto, foi mantida e uma "proposta de reestruturação", de novembro de 1999, além de descaracterizá-lo, deixava isso claro. O movimento pela manutenção do PET continuou forte e com amplo apoio, o que levou finalmente, à preservação do mesmo e impediu sua descaracterização (MULLER, 2003; MELO FILHO, 2019). A normalização, entretanto, foi gradual e até 2004 ocorreram atrasos periódicos no pagamento das bolsas. Esses atrasos acarretaram problemas para a realização das atividades do grupo devido ao término do curso por alguns bolsistas e o adiamento dos processos de seleção de novos bolsistas, dadas às incertezas quanto ao futuro do Programa.

Ainda assim, com auxílio da Universidade muitas das atividades do grupo continuaram sendo realizadas e os bolsistas participaram, em 2000, do II SIMPOPET e do IV Encontro dos Grupos PET de Ciências Biológicas de Minas Gerais, realizado em Belo Horizonte. Nesta ocasião, o grupo aproveitou 
para visitar o Museu de Ciências Naturais da PUC/MG, o Palácio das Artes e o Parque Nacional da Serra do Brigadeiro. O grupo ainda enviou três representantes ao ENAPET, que acontecia concomitantemente à Reunião Anual da SBPC.

Em 2002, o grupo se empenhou no desenvolvimento de atividades que não exigiam muitos recursos financeiros, tais como a realização de aulas de reforço escolar em Ciências para alunos do ensino fundamental de uma escola pública de Viçosa. Outras atividades desenvolvidas foram a organização e o desenvolvimento de uma Semana do Meio Ambiente e a Comemoração do Dia do Biólogo. Essas atividades foram realizadas com a colaboração dos Departamentos diretamente envolvidos com a coordenação do Curso, que liberaram cotas de xérox, papel e outros materiais de papelaria, pois, neste período, os grupos não dispunham de recursos de custeio. Ressalta-se também, a colaboração de diversos professores da Universidade, com a doação de livros e revistas científicas e realização de palestras e cursos de interesse do grupo e demais alunos do curso.

A partir de 2002, inicia-se um período de lenta regularização do Programa (MELO FILHO, 2019). Nesse sentido, em 2002 foi publicada a Portaria 647/2002, que estabeleceu as diretrizes de acompanhamento e avaliação do Programa (BRASIL 2002). Em 2003 foi aprovado um novo Manual de Orientações Básicas - que foi atualizado, pela última vez, em 2006 (BRASIL 2006) - e a mudança de nome do programa para "Programa de Educação Tutorial". Particularmente importante foi a aprovação da Lei no 11.180 (23/09/2005) que instituiu oficialmente o Programa e as Portarias n⿳3 3.385/2005 e n 1.632/2006 que o regulamentaram (BRASIL, 2005; 2006).

Em junho de 2006, o professor José Lino Neto substituiu o professor Lucio na tutoria do Programa.

Apesar dos constantes atrasos no pagamento de bolsas e das taxas acadêmicas, de 2006 a 2009, o grupo, além das atividades realizadas rotineiramente, promoveu um Simpósio sobre "Educação para a promoção da qualidade de vida" (2006). Em 2007, em comemoração ao bicentenário do nascimento de Charles Darwin e ao sesquicentenário da publicação de sua obra A origem das espécies, o grupo idealizou um ciclo de palestras sobre "A vida e obra de Charles Darwin”. Em 2008, o "Projeto Darwin" incluiu palestras e várias oficinas relacionadas com o tema "evolução" e "aprendendo a ensinar evolução". O grupo ainda selecionou vários livros sobre evolução para serem lidos e discutidos. Já em 2009, foram promovidas palestras sobre "Bioética" e "As ênfases do Curso de Ciências Biológicas da UFV". Durante esta última palestra, foi discutida a estrutura do Curso de Ciências Biológicas na UFV.

O grupo também participou do Encontro dos Grupos PET de Ciências Biológicas de Minas Gerais (2006 e 2008) e do ENAPET (2008) e organizou o Sudeste PET de 2007 e o Encontro dos Grupos PET de Ciências Biológicas de Minas Gerais de 2009. Em 2009, entretanto, devido à demora do envio dos recursos de custeio, o grupo não participou nem do Sudeste PET e nem do ENAPET, mas, conseguiu participar do UAI PET em Lavras-MG. 
A viagem técnica a uma base do projeto Tamar, prevista no planejamento de 2009, também teve que ser adiada, pelo atraso na liberação dos recursos para custeio. Entretanto, ainda em 2009, o grupo conseguiu visitar a cidade de São Paulo e conhecer o Museu de Zoologia da USP, o Zoológico, o Instituto Butantã e o Parque da Ciência.

Segundo o Prof. Lino,

um dos maiores desafios enquanto tutor do grupo foi justamente executar algumas das atividades planejadas com recursos cada vez menores e liberados quase sempre no final do respectivo ano civil.

Novos Ciclos de Palestras foram organizados (2010, 2011, 2012, 2014), além do "Simpósio em Ciências Forenses" (2013). Porém, devido aos atrasos na liberação de recursos para custeio nos anos de 2011, 2012 e 2016, a não liberação dos mesmos em 2010 e corte de 50\% no valor do mesmo em 2015, essas atividades deixaram de ser realizadas. Isto ocorreu porque não foi mais possível custear a vinda de profissionais de outras instituições, indispensáveis para a concretização das mesmas.

Do mesmo modo, a disponibilização tardia dos recursos de custeio para os grupos foi determinante para o cancelamento do XIX PET Pão de Queijo, que seria realizado no Campus de Pontal da Universidade Federal de Uberlândia. Desde então, o PET Pão de Queijo não vem mais sendo realizado. Este atraso também impediu a participação do Grupo no ENAPET, em 2016.

Em setembro de 2016, a Profa. Mara Garcia Tavares assume a tutoria do Programa em substituição ao professor Jose Lino Neto. Desde então, a Profa. Mara tutora o grupo na realização de atividades que complementem a formação acadêmica/científica global dos petianos. Muitas das ações que vinham sendo desenvolvidas tradicionalmente, tais como as apresentações de seminários, os debates, as discussões de livros de interesse geral continuaram sendo realizadas. Grande importância tem sido dada aos seminários apresentados pelos bolsistas, atividade que muito contribui para o desenvolvimento da capacidade de falar em público, desinibição e eficiência na transmissão de conhecimento. Os temas dos seminários atraem alunos que não são bolsistas do PET e isso, além de complementar a formação dos acadêmicos, reforça a interação do PET com os demais alunos do Curso.

Outras atividades que reforçam essa interação com os demais alunos do curso são: a recepção aos calouros na época da matrícula, a organização e divulgação entre todos os alunos do Curso do "Informativo PET/BIO", a comemoração do "Dia do Biólogo", a "Semana da Biologia” e a organização de palestras e "Cursos Extracurriculares”. Atualmente, esta integração com os alunos do curso tem sido favorecida pela divulgação das atividades do grupo nas suas redes sociais (Instagram: @ petbiologiaufv; Facebook: PET Biologia UFV; Blog: petbioufv.blogspot.com), além da utilização dos murais do PET/Biologia existentes na UFV.

O grande envolvimento da atual tutora com atividades de ensino e extensão tem dado ênfase às atividades nessas áreas, sem descuidar da formação dos bolsistas em outras áreas, como pesquisa e cultura. Entende-se 
que atividades de extensão são importantes para a formação dos futuros profissionais, principalmente, quase se considera o fato de que alunos do Bacharelado e da Licenciatura em Ciências Biológicas participam do PET/ Biologia.

Nas palavras da Professora Mara,

nessas situações [desenvolvimento de atividades extensionistas] os petianos se envolvem diretamente com a comunidade e podem, mais do que ensinar, aprender. Podem vivenciar situações diversas, muito diferentes das que, rotineiramente, vivenciam em casa ou na Universidade e somar essas experiências à sua formação profissional e pessoal. Tudo isso, com certeza, leva á reflexão e amadurecimento do indivíduo.

Mais recentemente, o grupo iniciou o oferecimento de um "Curso de Férias" para alunos de segundo grau, em parceria com os PETs Bioquímica e Nutrição. O objetivo do curso é despertar o interesse de alunos do Ensino Médio pelos cursos superiores oferecidos pela UFV. Para isso, um tema comum é escolhido e trabalhado interdisciplinarmente pelos três grupos PETs. Os resultados do Curso realizado em 2018 foram apresentados no Sudeste PET de 2019.

A partir de 2016, os atrasos no pagamento das bolsas têm sido menos frequentes do que os relatados em períodos anteriores e assim, o grupo tem conseguido alcançar os objetivos propostos e realizar suas atividades de maneira mais satisfatória. Porém, com os recursos para custeio reduzidos a $50 \%$ do que seria o esperado, desde 2015, o grupo tem encontrado dificuldades para realizar atividades que impliquem em viagens. Outra atividade que tem sido comprometida, com a redução do custeio é a participação nos encontros regionais e nacionais dos grupos PETs, realizados anualmente. A participação nessas atividades, assim como visitas a instituições acadêmicas e culturais são muito importantes para os bolsistas, especialmente, no caso da UFV, uma Universidade localizada longe dos grandes centros. A alternativa encontrada, longe de ser considerada ideal, tem sido o envio de representantes para o Sudeste PET e o ENAPET.

Em 2019, em razão da comemoração dos 35 anos do PET/Biologia da UFV, o grupo atualizou o banco de dados dos egressos do Programa, atividade indispensável para avaliação dos resultados alcançados, que serão discutidos abaixo.

\section{Resultados obtidos ao longo dos 35 anos de existência do PET/Biologia da UFV e Perspectivas}

Nestes 35 anos, passaram pelo programa 172 discentes. Destes, 89 já se encontram no mercado de trabalho, sendo que 35 deles estão atuando como professor no Ensino Superior, a grande maioria em Universidades públicas. Outros 24 ex-petianos são pesquisadores em empresas públicas de pesquisa (EMBRAPA, Fundação Ezequiel Dias - FUNED, Instituto René Rachou) e 12 são professores da Educação Básica. Quatro trabalham em outras empresas, cinco atuam como biólogos e nove exercem atividades diversas. 
Cinco egressos estão realizando Pós-doutoramento, 22 estão em Programas de Pós-graduação e 35 ainda não terminaram a graduação e estão realizando estágios em diversas áreas, de acordo com os interesses pessoais.

Doze ex-petianos não completaram o curso de Ciências Biológicas da UFV (cinco mudaram de curso, seis abandonaram o curso e um foi desligado) e não foi possível obter informações sobre a atuação profissional de nove ex-bolsistas,

Dos 89 ex-petianos que já ingressaram no mercado de trabalho, 81 fizeram pós-graduação (17 concluíram o Mestrado e 64 o Doutorado). Dos egressos, 85 (94,4\%) continuam atuando na área de Ciências Biológicas.

O tempo médio que os ex-petianos e os demais alunos do curso levaram para realizar seu curso de graduação foi praticamente igual (5,17 e 5,07 anos, respectivamente). Esse fato pode ser explicado pela própria organização da matriz curricular do Curso, que possui uma série de disciplinas que apresentam pré-requisitos. Esta organização exige a realização de disciplinas maneira sequencial, não possibilitando aos alunos antecipar a realização das mesmas. Adicionalmente, muitos dos alunos (tanto petianos como não petianos) cursam a licenciatura e o bacharelado, concomitantemente.

O rendimento acadêmico foi calculado como é usual na UFV, pelo "coeficiente de rendimento acumulado" (CRA) e diferiu entre os dois grupos analisados. Os graduados que participaram do PET tiveram CRA=83,8, enquanto os demais graduados do curso de Ciências Biológicas tiveram CRA=78,5. Outro parâmetro que diferiu quando se comparou os dois grupos foi a taxa de evasão. A análise realizada demonstrou que 6,98\% (12/ 172) dos integrantes do PET não concluíram o curso de Ciências Biológicas, enquanto a taxa de evasão foi de 38,3\%, entre os demais alunos do Curso. Em resumo: os bolsistas do PET realizaram seu curso em tempo semelhante aos demais alunos; obtiveram melhor rendimento acadêmico e tiveram taxa de evasão bem menor que os demais alunos do curso de Ciências Biológicas.

Esses dados mostram a influência positiva do Programa sobre a formação acadêmica dos discentes do Curso. Considera-se, portanto, que as atividades desenvolvidas e a atuação em grupo contribuem para manter/ aumentar a motivação dos alunos ao longo de todo o curso e estimular os estudos.

A importância do Programa para a formação profissional dos egressos pode ser avaliada, também, pela análise dos depoimentos abaixo:

... o PET Bio UFV me trouxe grandes desafios e muitos aprendizados. Além de ampliarem minha formação acadêmica, técnica e científica, as atividades permitiram que eu conhecesse e desenvolvesse habilidades/competências e, ainda, que eu vivenciasse experiências que me fizeram enxergar a pluralidade de ideias e de pensamentos como algo enriquecedor. Por isso, as atividades realizadas em grupo são minhas melhores lembranças. Hoje, nas minhas relações enquanto ser humano, cidadã e servidora/professora de uma Universidade Pública procuro praticar os aprendizados e inspirar outras pessoas com atitudes que valorizem a ciência, a formação ampla do indivíduo, o respeito às diferenças, a generosidade e a empatia.

Petiano(a) 1 
Foram quatro anos de trabalho no PET-BIO UFV, uma experiência única e gratificante, que contribuiu de forma muito positiva para o meu crescimento pessoal e profissional. A interdisciplinaridade das diversas atividades realizadas me permitiu desenvolver habilidades importantes em vários aspectos da minha vida: senso de liderança, responsabilidade, organização, desenvoltura, além do trabalho em equipe.

Petiano(a) 2

O fato do PET contribuir para evitar uma especialização precoce na formação profissional me preparou para ser uma aprendiz ao longo da vida. E também abriu minha cabeça para me interessar e aprender sobre diversos saberes. Além das ciências biológicas, até hoje me interesso e aprendo sobre arte, literatura, história, cultura. A intensidade da vida petiana me ensinou importantes lições em como gerenciar meu tempo e também em como me dividir em diversas atividades. Realizar atividades em grupo, debater e dividir as responsabilidades de tomar decisões me ensinou a trabalhar em equipe.

Petiano(a) 3

Percebe-se assim, que a metodologia adotada no Programa propicia oportunidade para que novos conhecimentos sejam adquiridos ao longo do tempo de permanência do bolsista no mesmo. Isso enriquece sua formação geral, melhora sua capacidade de trabalhar em equipe e de resolver problemas, aumentando sua criatividade e despertando novos interesses.

Ao longo desses 35 anos, algumas características do Programa e atividades realizadas pelo grupo foram sendo modificadas em consequência das mudanças da realidade, das trocas periódicas de bolsistas e de tutores, das expectativas dos petianos e das mudanças de concepção filosófica do Programa. Outras atividades, porém, vêm sendo mantidas ao longo do tempo e essa dinâmica reflete no amadurecimento do grupo, no seu reconhecimento institucional e para que os objetivos do Programa continuem sendo alcançados.

\section{CONCLUSÕES}

\section{O Futuro}

Quando o PET foi criado, pretendeu-se reproduzir a exitosa iniciativa do diretor da Escola de Comércio de Belo Horizonte, então transformada na Faculdade de Ciências Econômicas da UFMG (FACE). Essa iniciativa levou à formação de um grupo de profissionais, que teve e tem importante papel no desenvolvimento de Minas Gerais e do Brasil. Nessa ocasião (década de 60), iniciava-se no Brasil a implantação dos Programas de PósGraduação e parte do sucesso dos egressos do grupo da FACE, deveu-se ao sucesso dos mesmos nos processos seletivos para ingresso em Programas de Pós-Graduação.

Hoje, a despeito do grande número de estudantes em Programas de Pós-Graduação, os desafios relacionados à formação de pessoal, altamente qualificado e capacitado para assumir a liderança na solução dos antigos e novos problemas, são grandes e exigirão muito esforço. Ressalta-se que esses desafios estão surgindo em função da globalização, das rápidas mudanças tecnológicas e, no momento, daqueles advindos das mudanças já ocorridas e daquelas que ocorrerão em consequência da atual pandemia. 
Neste contexto, pequenos grupos de estudantes, capazes de realizar atividades extracurriculares, sem comprometer seu desempenho acadêmico, como é o caso do PET, podem ter papel muito importante nas mudanças que levem a uma formação mais flexível de pessoal. Eles podem também, influenciar as mudanças curriculares que se farão necessárias para formação de profissionais adaptados à nova realidade. Por outro lado, algumas das modificações que se farão necessárias poderão, ser testadas nesses grupos, antes de serem implantadas nos currículos.

Como não se espera que o ritmo das mudanças diminua, e sim que se acelere, a manutenção desse tipo de Programa e sua adequação às novas realidades é cada vez mais importante para uma formação de pessoal capaz de assumir os desafios gerados por uma realidade em constante e rápida modificação.

Um dos problemas que precisará ser equacionado é a obtenção de recursos de custeio para a realização de atividades que envolvem o deslocamento de pessoal (bolsistas, tutor e profissionais de outras instituições, para a realização de atividades programadas pelo PET e indispensáveis para que seus objetivos possam ser atingidos). Parte dessas atividades poderá ser realizada “on line”. Entretanto, outras só podem ser realizadas com o deslocamento de pessoal, o que envolve custos. Outra atividade muito prejudicada pela falta de recursos é a aquisição de livros para a biblioteca do PET e equipamentos como computadores. Sem livros novos e equipamentos atualizados, as atividades do Programa serão sobremaneira prejudicadas, impedindo que seus objetivos sejam plenamente atingidos.

\section{AGRADECIMENTOS}

Agradecemos ao Fundo Nacional de Desenvolvimento da Educação (FNDE) pela manutenção do Programa de Educação Tutorial (custeio e bolsas) e à Universidade Federal de Viçosa, pelo constante apoio em todas as atividades desenvolvidas pelo PET/Biologia. Agradecemos também aos ex-tutores pela atenção e disponibilidade, ao ajudar a resgatar os dados utilizados para a confecção deste artigo. Adicionalmente, somos gratos a todos os ex-petianos que responderam o questionário elaborado. As respostas obtidas nos ajudaram a analisar os resultados alcançados pelo grupo, nesses 35 anos de existência e a atualizar o banco de dados do PET/Biologia da UFV.

\section{REFERÊNCIAS}

BRASIL. Ministério da Educação. Portaria n ${ }^{\circ}$ 647, de 11 de junho de 2002. Estabelece as diretrizes de acompanhamento e avaliação do Programa Especial de Treinamento - PET.

BRASIL. Ministério da Educação. Lei nº. 11.180, de 23 de setembro de 2005. Institui o projeto Escola de fábrica, autoriza a concessão de bolsas de permanência a estudantes beneficiários do Programa Universidade para Todos - PROUNI, institui o Programa de Educação Tutorial - PET, altera a Lei no 5.537, de 21 de novembro de 1968 e a Consolidação das leis de Trabalho - CLT, aprovada pelo Decreto-Lei $n^{\circ} 5.452$, de $1^{\circ}$ de maio de 1943, e dá outras providências. 
BRASIL. Ministério da Educação. Portaria n 3.385, de 29 de setembro de 2005. Dispõe sobre o Programa de Educação Tutorial - PET.

BRASIL. Ministério da Educação. Portaria No 1.632, DE 25 de setembro de 2006. Dá nova redação ao $\S$ $2^{\circ}$ do art. 12 da Portaria n 3385 de 29 de setembro de 2005, que dispõe sobre o Programa de Educação Tutorial - PET.

BRASIL. Ministério da Educação. Secretaria de Ensino Superior. Manual de Orientações Básicas - PET. 2006. Disponível em: <http://portal.mec.gov.br/ index.php?option=com_docman\&view=download\&alias=338-manualorientabasicas\&category_slug=petprograma-de-educacao-tutorial\&Itemid=30192> . Acesso em 10 mar 2020.

BRASIL. Ministério da Educação. Portal MEC. 2020. Disponível em: <http://portal.mec.gov.br/pet/>. Acesso em: 10 mar 2020.

CASTRO, C. M. O PET visto por seu criador. Ensaio. 2001. Disponível em: <https://www.face.ufmg.br/ institucional/pet.html>. Acesso em: 09 mar 2020.

DESSEN, M. A. O programa especial de treinamento - PET: evolução e perspectivas futuras. Didática, v. 30, p. 27-43, 1995.

MELO FILHO, J. F. Programa de Educação tutorial: trajetória, desafios e articulações. Revista Eletrônica do Programa de Educação Tutorial - Três Lagoas/MS, v.1, n.1, p. 33-56, 2019.

MULLER, A. Qualidade no Ensino Superior - a luta em defesa do Programa Especial de Treinamento. Rio de Janeiro RJ: Garamond. 2003.

Submetido em: 25/09/2020 Aceito em: 29/10/2020 